\title{
Hydraulic vs. Electric: A Review of Actuation Systems in Offshore Drilling Equipment
}

\author{
W. Pawlus ${ }^{1,2}$ M. Choux ${ }^{1}$ M.R. Hansen ${ }^{1}$ \\ ${ }^{1}$ Department of Engineering Sciences, University of Agder, PO Box 509, N-4898 Grimstad, Norway. \\ E-mails: witold.p.pawlus@ieee.org; \{martin.choux; michael.r.hansen\}@uia.no \\ ${ }^{2}$ MHWirth AS, PO Box 413, Lundsiden, N-4604 Kristiansand, Norway. \\ E-mail: witold.pawlus@mhwirth.com
}

\begin{abstract}
This article presents a survey on actuation systems encountered in offshore drilling applications. Specifically, it focuses on giving a comparison of hydraulic and electric drivetrains along with detailed explanations of their advantages and drawbacks. A significant number of industrial case studies is examined in addition to the collection of academic publications, in order to accurately describe the current market situation. Some key directions of research and development required to satisfy increasing demands on powertrains operating offshore are identified. The impact of the literature and application surveys is further strengthened by benchmarking two designs of a full-scale pipe handling machine. Apart from other benefits, the electrically actuated machine reduces the total power consumption by $70 \%$ compared to its hydraulically driven counterpart. It is concluded that electric actuation systems, among other advantages, in general offer higher efficiency and flexibility, however, in some specific applications (such as energy accumulation or translational motion control) hydraulic powertrains are favorable.
\end{abstract}

Keywords: Offshore drilling, electric motors, hydraulic powertrains, actuation systems, drivetrain design.

\section{Introduction}

\subsection{Historical Perspective}

Electrification of onshore drilling rigs started in the 1930's (Rizzone, 1967). The overall trend back then was to shift from steam power to internal combustion engine power. However, despite the substantial cost of the equipment and the general fear of electricity that existed then, in several cases DC transmission was used (Rhea, 1946). The reason for internal combustion engine fitted rigs to become prevalent was their portability and improved efficiency, as compared to steam power solutions. The situation changed in the 1950 's due to a significant number of new offshore locations. Placement of machinery in such applications was dictated by vessel design and did not allow for such flexibility as for conventional land rigs, hence it excluded both steam power and internal combustion engines. What solved this problem was to apply locomotive traction type direct current (DC) equipment which paved the way for future development of electrified drill rigs, as reported by Strickler (1967), for instance. Initially, the generator was placed onshore and the electrical power was transmitted to the platform via submarine cable. Since then, many improvements have been made in designing optimized electric power systems for drilling and production platforms (Christensen and Zimmerman, 1986).

The history of electrification in the offshore drilling industry begins in 1947 when the first offshore platform was installed off the coast in Louisiana in $8 \mathrm{~m}$ of water (Stone et al., 2001). Although at that time the need for electrical systems was limited (e.g. to navigation sys- 
tems), further discoveries of oil and gas led to location of platforms further offshore. This in turn necessitated an increase in electricity generation on platforms to meet growing requirements to include living quarters and associated amenities (cooking, air conditioning, lighting, etc.) offshore. Traditionally, starting from the 1950's, gas turbines or engines were used for power generation and - by coupling to mechanical drives for load handling (Voltz et al., 2004). An alternative approach is to use electric power to supply machinery which manipulates the payload and to apply a separate energy source (typically gas turbines) for power generation. This solution is the most popular nowadays. Normally, actuation types which take advantage of electric motors are variable frequency drives (VFDs) and hydraulic drives, as described by Voltz et al. (2004).

\subsection{Overview on Actuation Systems}

The idea to use gas turbines as prime movers to turn alternating current generators which drive all major drilling components of offshore rigs has a well-proven track record in the industry (Allen and Scott, 1966). At that time, the solution that provided for speed control was to apply a fluid coupling, i.e. a hydro-kinetic device with a primary rotor (a pump to add energy to the fluid) connected to the power source and a secondary rotor (to extract stored energy from the fluid) connected to the driven machine (Andrus et al., 1966). This solution, referred in this paper to as a hydraulic actuation / drivetrain, owes its popularity to a number of factors. According to Janocha (2004), fluid power systems are capable of providing high forces at high power levels simultaneously to several actuating locations in a flexible manner. This results in higher torque / mass ratios than those available from electric motors, particularly at high levels of torque and power (Bak and Hansen, 2013c). Another advantage of a hydraulic actuation system is that any heat generated at the load is automatically transferred to another location away from the point of heat generation, by the hydraulic fluid itself, and effectively removed by means of a heat exchanger (Wang and Stelson, 2015). These features together with total automation capabilities and accessibility as well as explosion proofness made hydraulic drives a primary solution for offshore drilling applications since the 1960's.

However, for some offshore applications the disadvantages of fluid power systems are more significant than their benefits. Due to friction and nonlinearities of valves, variations in fluid viscosity, and stiffness, fluid power systems are more nonlinear than electrical actuation systems and more prone to oscillations. These negative factors cause additional difficulties for a control system design (Bak and Hansen, 2013b). Other challenges include leakage, noise, or difficulties in synchronization of several degrees of freedom (Bak and Hansen, 2013a). Finally, when the necessary accessories are included, fluid power systems might be by large more expensive and less portable than electrical actuation systems. In the past it was not possible to replace hydraulic actuators by alternating current (AC) drives due to the limited control features the latter solution offered. Even though when Blaschke (1972) introduced novel methods to control AC motors, it was not an industrially mature technology yet. Moreover, although DC drives provided sufficient control characteristics, they were not desired solutions neither due to high cost, maintenance, and risk of spark generation.

Nevertheless, enhanced control strategies of AC motor drives and recent advancements in power electronics (mainly development of semiconductor switching devices that started in the 1980s) made VFDs more popular and accessible (Depenbrock, 1985), (Tiitinen and Surandra, 1996), (Geyer et al., 2009) and (Papafotiou et al., 2009). Cost-effectiveness of VFDs and use of convenient power source distinguish them from other types of actuation systems. They are especially suitable for petrochemical industry, since there is virtually no risk of electric spark generation or arcing. The main advantages of VFDs are high reliability, high robustness, easy maintenance, long life and low cost (Kozlowski, 2013), (Swamy et al., 2015), (Seggewiss et al., 2015). These are the reasons for electric powertrains to become increasingly popular in the offshore drilling business. A typical drivetrain which uses variable speed drives is illustrated in Figure 1.

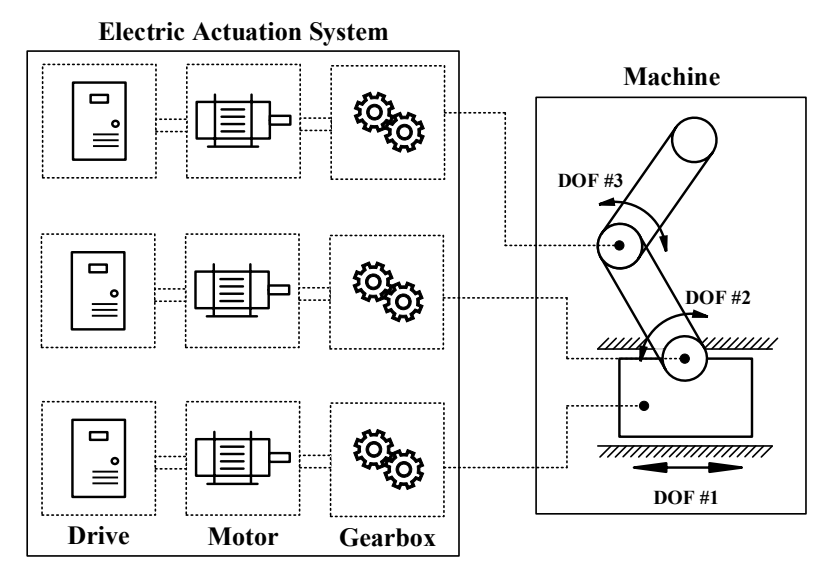

Figure 1: Conceptual representation of electric actuation system 


\subsection{Contributions}

Given an increasing attention of offshore drilling industry to all-electric systems and numerous publications concerning this topic which are spread throughout multiple publication channels, both academic and industrial, the current paper presents a review of electric actuation systems in offshore drilling applications within a single comprehensive study. Although in the literature there are surveys concerning offshore industry and:

- noise emission of equipment (Rahman and Abdullah, 1991)

- faults on induction motors (IMs) (Thorsen and Dalva, 1995) and (Mendel et al., 2009)

- wireless technology (Petersen et al., 2008)

- needs for technological development (Springett et al., 2010)

- increase of value robustness (Allaverdi et al., 2013)

- actuation types of intelligent completion systems (Potiani and Motta, 2014)

- heave compensation systems (Woodacre et al., 2015)

- electric ship propulsion (Hansen and Wendt, 2015)

- diagnostics and prognostics of offshore wind turbines (Kandukuri et al., 2016)

not much work is reported on benchmarking electric and hydraulic drives in a broader perspective, specifically for offshore drilling applications. The current paper fills this gap. In addition, the following three contributions of this study are highlighted:

1. Special emphasis is given to comparative analysis of hydraulic and electric actuation systems.

2. A case study is presented to benchmark key performance indicators of a gantry crane pipe handing machine available as both hydraulically and electrically driven configurations.

3. Potential of these powertrain solutions is assessed from the perspective of two emerging fields of application: subsea drilling / production and drilling systems automation.

The paper is organized as follows. Section 2 illustrates applications of electric actuation systems in offshore drilling business and underlines challenges associated with their design and operation. On the other hand, current innovations within the hydraulic powertrains are presented in Section 3. Sections 4 and 5 focus on safety, environment, cost, and maintenance related issues which arise when using a particular powertrain type. Topics that have recently attracted considerable attention, i.e. drilling activities in the Arctic, subsea drilling and production systems, as well as drilling automation and robotics are discussed from the perspective of drivetrain design in Sections 6, 7, and 8 . Section 9 identifies possible future trends for development of offshore motion control systems. A case study of electrification of the actuation system of an existing full-scale pipe handling machine is demonstrated in Section 10. The last Section outlines the conclusions.

\section{Electric Motor Drives in Offshore Industry}

\subsection{Overview}

A number of successful examples show that oil and gas producing plants may now rely to a higher degree on electric drives - see for instance the works done by Thorsen and Dalva (1995), Gallant and Andrews (2006), Rahimi et al. (2011), and Pawlus et al. (2014b). Williams (1991) outlines advantages and disadvantages of both hydraulic and electric top drive systems with a special emphasis on their performance and productivity. Since in hydraulic actuation systems energy changes its form more often, their overall efficiency is lower compared to electrically driven machines. Williams (1991) indicates that for the same top drive application the electrical system is much more efficient, by nearly $21 \%$. In addition, the key to reliability of the hydraulic system is cleanliness of oil. This of course involves additional expenses on appropriate filtration in both high pressure and return systems, as well as on a reservoir that will maintain clean oil.

Traditionally, hydraulic drives take the major lead in applications where high power density is required (Ottestad et al., 2012). To address the issue of generating high power from linear actuators, a concept of a permanent magnet linear actuator combined with a double gas spring is introduced by Ummaneni et al. (2007). Similarly, Zhang et al. (2012) presented a hammer drilling system driven by a tubular reciprocating translational motion permanent magnet synchronous motor. Gas springs make it possible for the piston to oscillate at high frequency. In addition, permanent magnets allow to produce large electromagnetic force, which, combined with large stroke lengths, is particularly useful in drilling applications. This concept could also be utilized in ocean wave power extraction to convert low speed, high force power to high speed, low 
force power.

Rivenbark et al. (2007) describe a problem of controlling wellhead gate valves by hydraulic actuators. They were operated from a pneumatically powered control panel which used electrically driven compressors to generate the instrument air. Not only such a solution was found to be inefficient due to losses associated with energy conversion but it was maintenance intensive as well. Therefore, an all-electric system that uses electric gate-valve actuators was proposed to overcome these historical difficulties. It eliminated the risk of leakage of fluid / gas, provided a clean power source, and made control and response times independent of temperature and fluid / gas displacement. In general, the all-electric system is a solution that is less complex, as it contains fewer subsystems - see Figure 2.
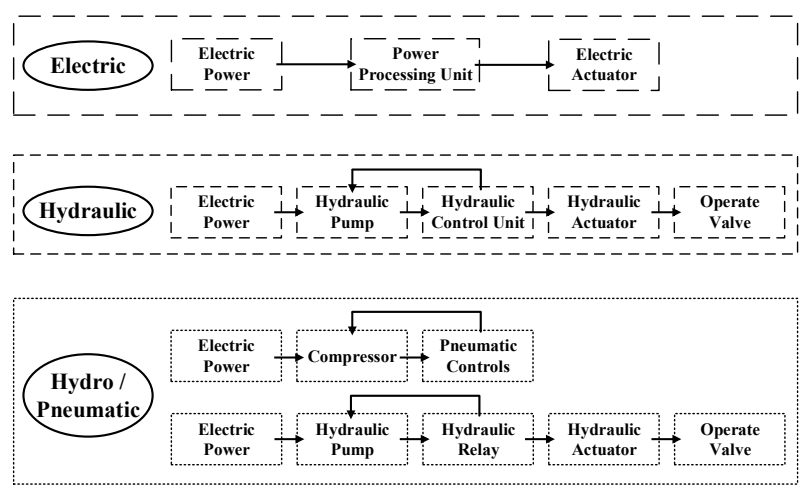

Figure 2: Comparison of complexity levels of popular actuation systems (Rivenbark et al., 2007)

Smooth control and silent operation that variable speed AC drives provide is recognized in shipping and marine sector as well (Sakuraba et al., 1992). Recently, all-electric vessels have become increasingly popular with dynamic positioning (DP) systems receiving special attention - see for instance (Yadav et al., 2014) and the references therein. A solution with a variable pitch propeller and a fixed rotational speed has been the most popular so far. What is more beneficial, however, is to fix pitch propeller and control the rotational speed instead, since in majority of cases the thrust needed is minimal (which reduces the shaft speed) (Leira et al., 2002). This results in lower energy consumption, as the electrical systems only require the power that is needed for the work, contrary to hydraulic drives which normally provide full torque at all speeds, causing the supply to operate at full power at all times.

As exploration of new offshore oil and gas fields is moving into deeper waters, marine operations related to development, completions, and production activities require more power and design of optimal power generation systems (Craig and Islam, 2012) and (Marvik et al., 2013). Since technology which enables well control in ultradeep water has emerged, there is observed the trend to move all infrastructure subsea. It was already in the 1990's when Jernstrøm et al. (1993) recognized that an all-electric control system for subsea well control would be simpler and less expensive compared to a conventional electro-hydraulic control system. Some advantages of using this new solution are: higher flexibility when expanding an existing system, removal of significant environmental, technical, and economical problems associated with hydraulic fluids, and possibility to develop marginal fields at large distances from processing facilities. The topic of subsea systems and installations deserves a closer attention when seen from the perspective of electric powertrains, and is therefore widely discussed in Section 7. Another field that is expected to play a key role in the future and which is related to electric actuation systems is drilling automation (Rassenfoss, 2011), covered in Section 8.

\subsection{Challenges in Design and Drilling Operations}

One of the challenges that arises with an increased use of electric motor drives in offshore applications, is susceptibility to poor power quality in the form of voltage notches and overvoltage ringing (Hoevenaars et al., 2013). Such distortion might lead to failures in other equipment connected to the power distribution bus. It is therefore important to apply harmonic mitigation techniques such as filters discussed by Hoevenaars et al. (2013) and Hoevenaars et al. (2016) to ensure no power-quality problems. We elaborate more thoroughly on this topic in Section 4. Similarly, pressure oscillations in wells, caused by heave motion, present a serious threat to personnel and the environment, and a risk of a significant economic damage in case of loss of the well. Hence, appropriate vibration and oscillation mitigation techniques have to be applied to suppress pressure fluctuations (Albert et al., 2015). Drilling of complex curved boreholes in order to access unconventional reservoirs of oil and gas is associated with an additional problem of increased drag losses while drilling. To prevent borehole spiraling, a model-based control strategy is developed by (Kremers et al., 2016). Not only it guarantees the stable generation of complex curved boreholes but also needs only limited measurement data.

When designing electric drivetrains, an extra effort should be made to select an appropriate motor type. Generally speaking, induction motors are the most frequent in use because of their simple and rugged construction, and simple installation and control (Couper 
et al., 2012). Synchronous motors, on the other hand, offer slightly higher efficiencies than that of induction motors, the higher values at the lower speeds. They are particularly useful in high power and / or low speed applications, and usually have higher power density compared to induction motors (at the cost of higher price).

Electrically actuated offshore drilling machines are often designed overly conservative to work under cyclic loads, whereas, in reality, maximum load conditions acting upon them constitute only a slight share of total loads experienced during a lifecycle (Pawlus et al., 2014a). Of course, sensible over-dimensioning to account for unexpected events which are likely to occur in offshore environment is acceptable. What should not be tolerated, however, is to over-dimension drivetrain components due to the lack of information characterizing load conditions. To address this problem, Pawlus et al. (2016) presented an approach to estimate required full-scale motor torque using a scaled down experimental setup and its computational model. The discussed approach mitigates the effort of design engineers to select the best combination of components of an electric drivetrain by allowing to explicitly specify the required motor torque, which includes the effects of static and dynamic loads as well as friction. In addition, to reduce conservatism when designing electric powertrains, Pawlus et al. (2015) proposed a method to optimally choose elements of electric drivetrains from manufacturers' catalogs. The combination of components (namely, a motor, a gearbox, and a drive, as illustrated in Figure 3) that both satisfies design constraints and specifications as well as minimizes the total drivetrain costs is guaranteed to be the global optimum, in contrast to some other tools which may achieve only local optima.

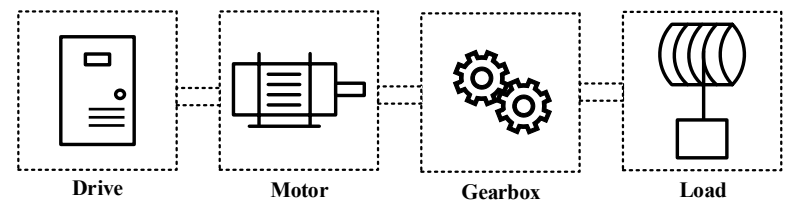

Figure 3: Design optimization problem of electric drivetrain (Pawlus et al., 2015)

\subsection{Summary}

The following main advantages of electric actuation systems are identified for offshore drilling operations (Adnanes, 2003):

1. Reduced fuel / energy consumption - especially when there is a large variation in load demand.
2. Less space occupation - increase of rig's payload.

3. Flexibility in location of actuators - electric power is supplied through cables, therefore an actuator could be placed independently on the location of the power generator.

4. Lowered noise - optimized operation of power generators.

5. Improved control features - accessible speed control of AC motor drives and limited nonlinearity of the system.

6. High positioning accuracy - convenient control of motion profiles.

7. No risk of leakages - removal of hoses, pipes, tanks, valves, pumps, etc.

8. Fewer maintenance tasks - no need to replace worn out hydraulic components and to retune control systems.

These benefits have to be, however, weighted up against the following drawbacks:

1. Lower power density - hydraulic actuators develop relatively large torques for comparatively small devices.

2. Fail-safe brake - in case of power loss a mechanical brake has to hold the load.

3. Additional components - harmonics reduction systems, transformers, extra cooling, etc.

4. Stall conditions - it is dangerous to operate an electric motor continuously at full load and low speed.

\section{Hydraulic Powertrains - Recent Developments}

There are many unique features of hydraulic drivetrains pointed out by Meritt (1967) that are still relevant compared to other types of control. The most significant ones are:

1. The fluid carries away the generated heat to a convenient heat exchanger.

2. It acts as a lubricant as well and extends life of drivetrain components.

3. Hydraulic actuators develop relatively large torques for comparatively small devices. 
4. Torque to inertia ratios are large which results in high acceleration capabilities.

5. Actuators can directly be used for dynamic braking (with relief valves protection).

6. They can be operated under continuous, intermittent, reversing, and stalled conditions without damage.

7. Higher stiffness results in little drop in speed as loads are applied.

8. Energy storage is relatively straightforward with hydraulic / pneumatic accumulators.

9. Natural damping due to the compressibility of the hydraulic oil. This behavior makes the hydraulic actuators more tolerant of impact (shock) loads.

Apart from numerous proven examples of using hydraulic powertrains in the offshore drilling applications - see for instance (Bak, 2014) and the references therein - we would like to discuss some recent developments and innovative solutions that make hydraulic systems a tough competitor to all-electric drivetrains (Nordhammer et al., 2012).

An area that attracts significant attention of the industry is the use of variable speed drives in fluid pumping applications (Jahmeerbacus, 2015). It is considered to be more efficient solution for achieving adjustable flow rates compared to old-fashioned (but still popular) method to drive pumps by 3-phase induction motors operating at fixed speeds. However, what still might occur at low speeds and high static heads, is that pumps run at efficiencies that are far from the optimum. Therefore, adjusting the flow rate and total head within the best efficiency region of the pump by using appropriate induction motor control strategies becomes a challenge (Josifovic et al., 2014). Additional design factors such as serial or parallel connections of pumps and motors have to be considered to achieve the best possible system performance (Neufeld et al., 2014). Some other recent innovations to achieve lowcost, low-maintenance, and high-efficiency hydraulic solutions, involve fast switching digital valves (Roemer et al., 2015), robust control of hydraulic linear drives (Schmidt, 2015) or optimal design of hydrostatic transmissions (Pedersen et al., 2012). These examples show that hydraulic actuation systems are continuously being improved to increase performance specifications of fluid power solutions.

Finally, the conventional drilling rigs are known to waste the deposited potential energy during hoisting / lowering operations and active / passive heave compensation. However, there are efforts to store this energy in the form either available as pressure boost in hydraulic systems or electricity induced during regenerative braking (Lujun, 2010). So far, the capabilities of hydraulic / pneumatic accumulators are superior to energy storage options that modern battery systems offer (Bender et al., 2013). Especially, when offshore operating conditions characterized by high loads and heave motion are considered.

\section{Safety and Environment}

Actuation systems that provide for high fuel efficiency and lower emissions are preferred nowadays to mitigate the greenhouse effect and address environmental concerns of governments and various agencies (Kim and Chang, 2007). Standard hydraulic power units (HPUs) which supply fluid flow in hydraulic actuation systems are known to have higher power demands than allelectric systems. This results in higher energy consumption and $\mathrm{CO}_{2}$ emissions (Sun and Kuo, 2010). The effect of reduced environmental footprint is more pronounced for applications utilizing VFDs when operating at load conditions different than the rated (Kim et al., 2010). Hence, variable speed electric drivetrains not only improve efficiency of driven equipment and allow for continuous process control over a wide range of speeds but also decrease the emissions of greenhouse gases (Yoon et al., 2009). In addition, the problem which completely disappears in applications involving the use of electric powertrains is leakage from hydraulic pipes, hoses, pumps, etc. (Rivenbark et al., 2007).

The survey done by Rahman and Abdullah (1991) points out that the major sources of noise on drilling rigs are ventilation ducts, generators, hydraulic pumps, and the drawworks on the rig floor. The study revealed that the noise in offshore applications is a complex issue both in terms of vibration and structural noise as well as personnel noise exposures. It is therefore essential not only to install acoustic panels or enclosures in highly sensitive areas (e.g. to protect personnel in their living quarters) but also to substitute / upgrade equipment producing excessive levels of acoustic emission. Replacing hydraulic drivetrains or moving them away from personnel working areas has been identified by Rahman and Abdullah (1991) as a key factor to improve noise control on offshore production platforms and drilling rigs.

Additional critical safety issue related to an increasing use of $\mathrm{AC}$ and DC electric drives in marine applications (e.g. electric propulsion or offshore drilling operations) is harmonic distortion (Hoevenaars et al., 2010). Since VFDs draw current in a nonlinear or sinusoidal manner, they can introduce excessive levels of both current and voltage harmonics. Harmonics are dangerous especially in oil refineries and oil produc- 
tion platforms, i.e. in zones 1 and 2 explosion-proof motor installations, see IEC (2014) and IEC (2015). Degradation of bearing lubrication caused by rotors overheated by harmonics might lead to frictional sparking. Similarly, a risk of explosion increases as quality of shaft seals decreases. Therefore, specific requirements are given in international standards in an attempt to protect against this risk and to keep voltage distortion below acceptable levels, for instance (IEC, 2002), (IEC, 2010), (ABS, 2006), (DNV, 2005). Typically, the techniques to mitigate total harmonic voltage distortion (THDv) involve application of filters or active front-end (AFE) drives and became a common industrial practice (Mindykowski et al., 2007). Finally, to ensure safe load handling / parking in case of loss of electrical power, proper brake mechanisms have to be applied. Traditionally, mechanical friction brakes that are costly and require maintenance have been used for AC motor drives (Kaufman and Kocher, 1984). They are a well-proven solution still used in many industrial applications (Ko et al., 2015). On the other hand, drive-by-wire systems without mechanical backup become increasingly popular in automotive and aerospace industries (Isermann et al., 2002). They are based on a number of redundant control systems that transfer electrical commands to electromechanical actuators, resulting eventually in a scheme that is usually not fail-safe but has fault-tolerant properties. In this regard, hydraulic actuators are more convenient to operate, since it is enough to design a fail-safe circuit which ensures that the actuator (e.g. a hydraulic cylinder) will stand still in case of hydraulic line rupture or power loss (Phillips and Laberge, 1984).

\section{Cost and Maintenance}

Shatto (1951) compared the individual costs of major parts of various transmission systems. Already back then, for a rig under question, the electric transmission turned out to be slightly more cost-effective than the widely spread mechanical drives. In addition, the cost of initial investment did not indicate the maintenance savings that result from reduction of engine shock loads or overload, and the elimination of many chain drives and clutches. Similarly, such intangible effects on drilling costs and safety of operation as: simple control, the ability to meter all loads, and reduction of engine noise at the derrick floor, were impossible to be accurately assessed but they generally speak in favor of electric transmissions.

Nowadays, the initial investment of electric and hydraulic drives in offshore drilling applications is in most cases comparable. There are of course some applications when one solution is cheaper than the other
(Williams, 1991). However, given an increasing number of electric actuation systems in various industries (Christopoulos et al., 2016), it is expected that the cost of variable speed drives, motors, and associated power electronics systems will further decrease. Rivenbark et al. (2007), for instance, estimates that the total cost savings for the all-electric system to control well production exceeds $\$ 200000$ per well, over the traditional pneumatic / hydraulic system. The savings that are not included in this amount come from reduction of maintenance and service personnel and are difficult to be precisely assessed.

Similarly, there is evidence that all-electric systems are more compact and flexible than their hydraulic counterparts (Bak, 2014). This directly translates to cost savings, since, according to Christensen and Zimmerman (1986), platform deck area is valued at approximately $\$ 600-\$ 6000 / f t^{2}$, depending on the platform location, and for every pound in weight saved, $\$ 1-\$ 5$ of structural material are saved. Serious maintenance tasks require stopping platform production. The cost of this operation ranges from $\$ 37500 / h$ for small Gulf of Mexico platforms to $\$ 187500 / h$ for large North Sea platforms. It is therefore essential to limit service and maintenance activities to absolute minimum - something that is within the reach when using all-electric solutions.

\section{Arctic Operations}

\subsection{Hydrocarbons Reserves}

According to Ciechanowska (2011), shrinking global energetic supplies and a continuously growing demand on all kinds of fuels (especially on crude oil, natural gas, and oil-products) brought attention of international community to an enormous hydrocarbonic potential of the Arctic. Despite temporary interruptions and market difficulties, fossil fuels remain the dominant form of global energy, accounting for almost $80 \%$ of total energy supplies by 2035 (BP, 2016). In particular, the global oil demand is predicted to increase by almost $20 \mathrm{Mb} / d$ within the same time period. Hydrocarbon deposits available under the seabed of the Arctic Ocean locate it in the first place among all global waters with respect to presence of oil and gas resources (Zolotukhin and Gawrilov, 2011). It is estimated that in the Arctic there is $25-30 \%$ of global deposits of natural gas and $10-15 \%$ of global deposits of crude oil. Drilling activities have already started in Pechora (Pettersen, 2015) and Barents (Zacks Equity Research, 2016) Seas, to name just two most famous examples. Therefore, the Arctic Ocean is definitely going to play a key role in the near future when it comes to the shape 
of the global energy outlook.

\subsection{Environmental Challenges}

Oil and gas production in the Arctic depends on a complex set of variables (Harsem et al., 2011). Harsh winters with extreme temperatures and year-round ice represent highly challenging conditions for the oil and gas industry. In addition, a few more factors that make drilling in the Arctic difficult are: thick ice cover present for 4-12 months per year, frequent storms and strong gales, low temperatures reaching from $-20{ }^{\circ} \mathrm{C}$ to $-60{ }^{\circ} \mathrm{C}$, high seismic activity, and floating ice floes capable of destroying virtually every offshore installation. On top of that, governments are not willing to give out drilling licenses without proper consideration of the environmental impact of drilling in highly sensitive regions. Therefore, it is strongly recommended that the petroleum enterprises in the years to come invest in technology which makes exploratory drilling less difficult, more cost-effective, and environment friendly.

\subsection{Feasibility of Electric Systems}

As already mentioned in Section 2, AC motors controlled by VFDs are characterized by improved control features, reduced energy consumption, higher reliability over time, as well as minimal routine and preventive maintenance. These features, together with lower emissions and eliminated risk of oil leakages to sea water, cause VFDs to have a better impact on the environment, and directly correspond to the above mentioned strict requirements for actuation systems which are to be used in the Arctic environment.

\section{Subsea Infrastructure and Control Systems}

The trend of moving the production into deeper water and areas with hostile weather conditions has already been recognized by Rye (1972). Operation of control valves on subsea equipment such as blowout preventers (BOPs), satellite trees, and complex manifold systems requires suitable control systems. In addition, extra signals, such as production pressures and valves positions have to be made available to control system so that it can detect adverse conditions and perform its automatic shut-down in case of serious failures. Normally, the following subsystems are needed for a successful operation of a subsea control system:

$$
\begin{aligned}
& \text { - hydraulic power } \\
& \text { - communication }
\end{aligned}
$$

- electrical power.

Pipe (1982) describes that back then there were no known examples of application of electrical power to directly operate subsea systems. This, however, has completely changed over $2-3$ decades. For instance, the first all-electric subsea system in the Dutch sector of the North Sea has been already in operation in the 2000's (Abicht, 2010). A few reasons for electric actuation systems to become dominant over traditional hydraulic solutions in subsea equipment are: increased precision, increased energy efficiency, fewer converting processes, reduced risk of pollution, less potential failure points, smaller footprint, short response time, improved operability, extended monitoring possibilities, and enhanced maintenance, with the only drawback being identified as the limited track record. This, however, can be justified by the relatively new state of technology, and - given many advantages this solution offers - is going to change in the future. In addition, Aadland and Petersen (2010) mention that the overall trend is not only to replace / supplement the existing hydraulic subsea control systems with all-electric actuators but to move the production facilities from the sea surface into seabed. The electric actuation systems will certainly play a key role in such facilities operating in the Arctic, given the challenges described in Section 6 (Hazel et al., 2013).

\section{Drilling Systems Automation}

The level of automation in the drilling industry is still relatively low compared to other industries. It was only in the last decade when significant amount of research and development initiatives have been started in this field (Breyholtz and Nikolaou, 2012). Automation can be defined as reduction of workload of human operators by introduction of control systems and information technology. It goes one step beyond mechanization which only replaced human power by mechanical. As expected, automation of all stages of drilling process is a challenging task. To better understand different levels of automation and the role of the driller in such environment, Table 1 summarizes possible modes of automation based on automation strategies from the aviation industry.

The driller should be able to switch between different modes during a drilling operation so that at all times the driller is the absolute authority of the operation. The point is made here that "automation" must not be used interchangeably with "autonomy", since these two notions have totally different meaning, as it is clear from Table 1. Experiences from other industries show that increasing the mode of automation increases the 
Pawlus et al., "Hydraulic vs. Electric: A Review of Actuation Systems in Offshore Drilling Equipment"

Table 1: Modes of automation (Breyholtz and Nikolaou, 2012)

\begin{tabular}{|c|c|c|c|}
\hline Mode & Management Mode & Automation Functions & Driller Functions \\
\hline 6 & $\begin{array}{l}\text { Autonomous } \\
\text { Operation }\end{array}$ & Fully autonomous operation. & $\begin{array}{c}\text { No particular function. Operation goals are } \\
\text { self-defined. Monitoring is limited to fault } \\
\text { detection. }\end{array}$ \\
\hline 5 & $\begin{array}{l}\text { Management by } \\
\text { Exception }\end{array}$ & $\begin{array}{l}\text { The automation system chooses } \\
\text { operations and defines operation } \\
\text { goals, informs the driller, and } \\
\text { monitors responses on critical } \\
\text { decisions. }\end{array}$ & $\begin{array}{l}\text { The driller is informed of the system intent. } \\
\text { Must consent to critical decisions only. May } \\
\text { intervene by reverting to lower mode of } \\
\text { management. }\end{array}$ \\
\hline 4 & $\begin{array}{l}\text { Management by } \\
\text { Consent }\end{array}$ & $\begin{array}{l}\text { The automation provides coordinated } \\
\text { control of multiple control loops. }\end{array}$ & $\begin{array}{c}\text { The driller feeds the automation system with } \\
\text { a chosen operation, operation goals, and } \\
\text { desired values for key variables. }\end{array}$ \\
\hline 3 & $\begin{array}{l}\text { Management by } \\
\text { Delegation }\end{array}$ & $\begin{array}{l}\text { The automation system provides } \\
\text { closed loop control of individual tasks. }\end{array}$ & $\begin{array}{l}\text { The driller decides setpoints for the } \\
\text { individual control loops. Some tasks are still } \\
\text { performed manually. }\end{array}$ \\
\hline 2 & Shared Control & $\begin{array}{l}\text { The automation system could } \\
\text { interfere to prevent the driller from } \\
\text { exceeding specified boundaries. }\end{array}$ & $\begin{array}{c}\text { Envelope protection systems are enabled. } \\
\text { Decision support / advisory systems are } \\
\text { available. }\end{array}$ \\
\hline 1 & $\begin{array}{l}\text { Assisted Manual } \\
\text { Control }\end{array}$ & $\begin{array}{l}\text { Provides down-hole information } \\
\text { trends and detects abnormal } \\
\text { conditions in the well. Does not } \\
\text { intervene. }\end{array}$ & $\begin{array}{l}\text { The driller has direct authority over all } \\
\text { systems. Decision-making is computer aided. }\end{array}$ \\
\hline 0 & Direct Manual Control & Warnings and alarms only. & $\begin{array}{l}\text { The driller has direct authority over all } \\
\text { systems. Unaided decision-making. }\end{array}$ \\
\hline
\end{tabular}

overall operational and economic performance of the controlled process.

The oil and gas industry has always striven to improve both safety and profitability of drilling operations. Reaching these goals have recently become more difficult due to increased challenge and risk of recovering today's harder-to-reach reserves (Sadlier and Laing, 2011). Due to these obstacles, a need to automate drilling systems has emerged in order to improve rate of penetration (ROP) and repeatability of drilling process, as well as to mitigate risks associated with health, safety, and environment (HS\&E). In addition, as more experienced people retire from the industry, it is necessary to find ways to access the expertise regardless of human factors. A number of successful examples to reduce mean time between failure (MTBF), improve safety, performance, quality, reliability, consistency, and interoperability thanks to automation of drilling processes is presented by de Wardt et al. (2013).

However, to realize the vision of fully automated (and some day - autonomous) drilling operations, one should think of using such components and subsystems that acquire, process, provide information, and automatically execute instructions within a common information-sharing framework. Hence, automated control of drilling process can only be achieved with seamless communication and interoperability of various portions of the complete drilling package (Sadlier and
Laing, 2011). These features have to be supported by reliable decision-making systems to integrate real-time data with optimal control actions (Rodriguez et al., 2013).

Therefore, from the perspective of drilling automation, the favorable approach would be to unify and integrate different subsystems of drilling process, software solutions, and types of actuation systems. This is especially applicable when considering the fact that the level of complexity and integration of various parts of offshore installations constantly grows (Shuguang et al., 2015). Since offshore drilling machines driven by fully electric powertrains simplify design of actuation systems, they are more likely to faster reach certain levels of automation than their hydraulically actuated counterparts.

One step towards an increasing level of drilling automation is simulation based engineering (Pawlus et al., 2014c). Allowing the model of a designed system to grow to cover the complete process and all scenarios is necessary in order to test more sophisticated control algorithms in a virtual simulation environment before applying them on full-scale machinery (Downton, 2015). Such approach facilitates product development and shortens commissioning time by making it possible to immediately implement each subsystem of automation engineering in simulation. 


\section{Future Trends in Offshore Actuation Systems}

It is expected that electric actuation systems will constitute an increasing share of powertrain solutions in offshore drilling applications in the future. In particular, more attention should be devoted to selection of the best motor type for a given application - e.g. induction vs. permanent magnet motors (PMMs). Brinner et al. (2014) show that, on average, PMM uses $20 \%$ less energy than IM in applications that have high power demand. Therefore, it is anticipated that the number of installations equipped with such machines will increase so that the industry will formulate best practices and recommendations for selection of the optimal motor type given particular specification requirements.

In addition, considering the amount of research that is currently being done to develop linear electromagnetic actuators characterized by high power density and continuous force control (Kim and Chang, 2007), it is predicted that hydraulic linear actuators might become less popular. Many components, such as hydraulic pump, valve module, and connecting hoses, as well as relatively slow response times, are the negative features of hydraulic cylinder blocks. Their electromagnetic counterparts, on the other hand, already offer improved dynamic response, high accuracy, high efficiency, environmentally friendly design, and clean work area (Han and Chang, 2016). The only limiting factor is their lower power density but this is likely to improve considering their increasing popularity among various industries (Boglietti et al., 2009).

Finally, judging by the interest that the international community developed for the Arctic resources, it is highly probable that subsea production sites will dominate the drilling landscape in the years to come. Such solutions are desirable as they reduce or eliminate the surface production platforms, improve costeffectiveness, and lower threat to personnel (Craig and Islam, 2012). For the same reasons, drilling automation and robotic systems are expected to play a key role and significantly change the way we understand and design drilling and production processes today (Austigard, 2016). In both applications, all-electric systems will be superior to hydraulic drivetrains, given their advantages discussed in Sections 7 and 8 (Springett et al., 2010).

\section{Case Study - Gantry Crane}

\subsection{General Description}

The Gantry Crane illustrated in Figure 4 is designed for handling drill pipes from pipe deck to tubular shuttle and vice versa. The crane is equipped with a parallel yoke for single and dual pipe handling. The lifting yoke is attached to the horizontal lifting telescope. The trolley on which the lifting yoke is located is fitted with two winches: one for hoisting / lowering the parallel yoke and the other (manually operated) for utility operation. Main specifications of the machine are summarized in Table 2.

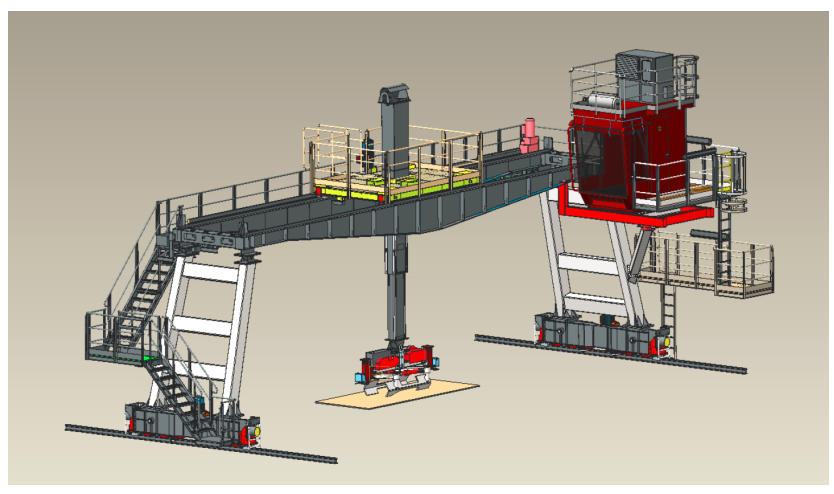

Figure 4: The Gantry Crane - courtesy of MHWirth AS

Table 2: Characteristic features of the Gantry Crane

\begin{tabular}{lc}
\hline Property & Value \\
\hline Safe working load (SWL) & $3.5 \mathrm{t}$ \\
\hline Gantry travel & $50.0 \mathrm{~m}$ \\
\hline Gantry rail span & $18.5 \mathrm{~m}$ \\
\hline Trolley travel & $12.0 \mathrm{~m}$ \\
\hline Trolley rail span & $2.3 \mathrm{~m}$ \\
\hline Telescope stroke & $3.7 \mathrm{~m}$ \\
\hline Total weight & $37.8 \mathrm{t}$
\end{tabular}

\subsection{Electric Motion Control}

The discussed Gantry Crane is available to customers as both hydraulically and electrically actuated system. The gripper on the parallel yoke is the only part of the machine that is driven by a hydraulic drivetrain in the electric version. Apart from it, there are 3 axes which are electrically actuated by VFD-controlled induction motors:

1. Crane travel using rack and pinion system.

2. Trolley travel using rack and pinion system.

3. Hoisting / lowering of parallel yoke using winch mechanism. 
There is one induction motor on each of the two Gantry Crane carriages - see Figure 5. Each of the two motors has a hydraulic fail-safe brake activated when loss of electric power is detected. The trolley trav-

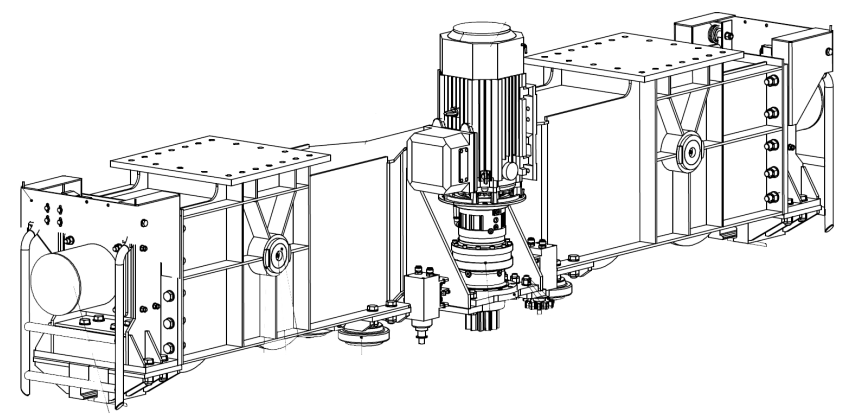

Figure 5: The carriage assembly

els horizontally on top of the main beam. Similarly to crane carriages, travel function of trolleys is performed by using rack and pinion system and electric drivetrains with the same mechanism for emergency braking. The telescopic arm consists of two rectangular hollow sections. The outer box is fixed to the trolley frame, whereas the inner box moves up and down. The trolley telescope is actuated by means of an electrically driven winch and wire sheave system. The wire runs from the winch to a sheave located on top of the outer box and then down to the inner telescopic box. The winch is fitted with the fail-safe brake as well, thus ensuring safe handling of loads in case of power loss. The complete subsystem is shown in Figure 6.

\subsection{Benefits}

Table 3 summarizes some of the most important differences between hydraulically and electrically actuated Gantry Cranes. Although this list is not exhaustive (e.g. it does not contain detailed information regarding frequency and cost of maintenance tasks) and presents only the most essential features, it clearly shows an advantage of using VFDs over traditional hydraulic drivetrains. Not only the electrically actuated machine offers a significant reduction of power consumption (no big-size HPU) but it also provides for improved control performance and weight reduction of the total system. The last feature is especially relevant for offshore applications, since according to (Christensen and Zimmerman, 1986), the platform deck area is valued at approximately $\$ 6500-\$ 65000 / m^{2}$ and every saved kilogram of weight yields a saving of $\$ 2-\$ 10$ on structural material (recall Section 5).

The electrically actuated system demands of course additional equipment and functions (e.g. fail-safe brakes) which are not required in the case of hydraulic

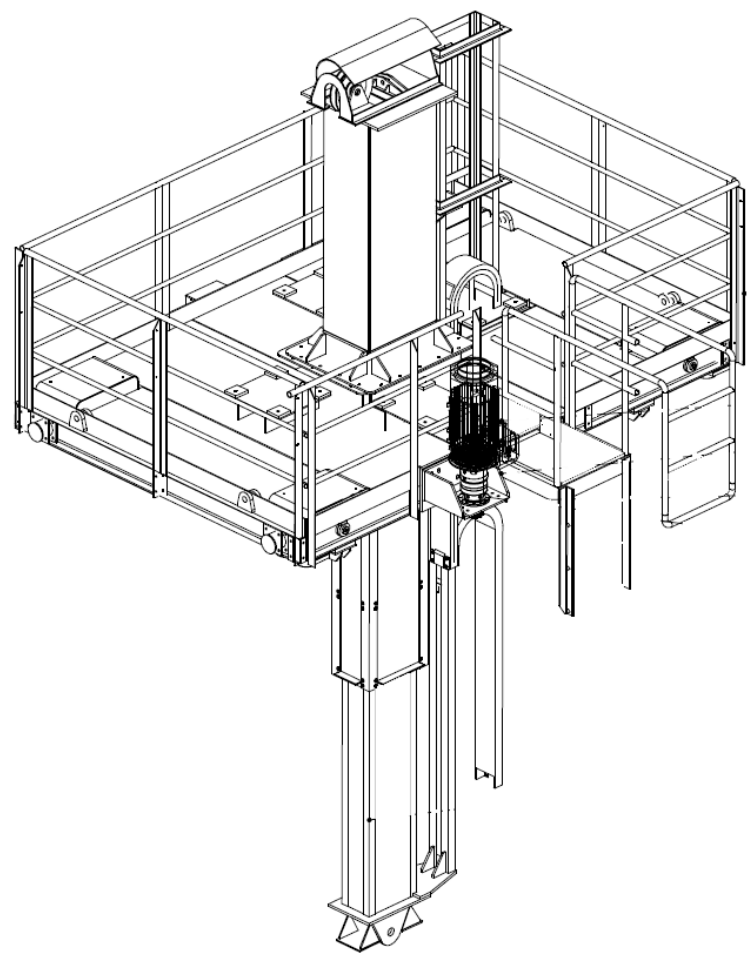

Figure 6: The trolley arrangement with the telescopic arm

Table 3: Advantages of the electrically actuated Gantry Crane compared to the hydraulically driven machine

\section{Mass}

$\checkmark$ Total weight reduced by $10 \%$.

Energy

$\checkmark$ Total power consumption reduced by $70 \%$.

$\checkmark$ Power optimization (higher speed at zero hook load).

\section{Environment}

$\checkmark$ Noise level reduced by $20 \%$.

$\checkmark$ Removal of high pressure hoses.

$\checkmark$ Hydraulic leakage and oil contamination reduced to minimum.

$\checkmark$ No need to warm up oil for operation in cold weather.

\section{Control}

$\checkmark$ Better dynamic control during load handling.

$\checkmark$ One VFD to control two winch motors.

$\checkmark$ No need for valve overlap correction / tuning due to wear of hydraulic system.

\section{Maintenance}

$\checkmark$ Lower volume of oil.

$\checkmark$ Conservation tasks of pipes, pumps, valves, etc. reduced to minimum. 
drivetrains, however, these drawbacks are of marginal relevance given the above advantages. In addition, although the initial investment is comparable for both electric and hydraulic systems, the first one offers significantly lower maintenance costs and reduced service tasks. The electrically actuated Gantry Crane indeed offers all the benefits that were identified in the literature survey and summarized in Section 2.3.

\section{Conclusions}

This paper presents a survey on actuation systems in offshore drilling applications. Contrary to previous works, this study is focused on electrically driven equipment and is not concerned with one specific machine design but, instead, it tries to focus on drilling equipment in general. In addition, not only academic publications are reviewed but - what authors believe to be equally important - a significant number of industrial case studies and research activities. In order to draw an informative picture describing the undergoing shift from hydraulically to electrically actuated drilling machines, state of the art in both the research front and the industrial applications was presented. In the authors' opinion, such an approach gives more credibility to the findings shown in this paper, since many industrial examples from the market are also discussed. Finally, the results of comparative analysis of hydraulic and electric drivetrains, based on theoretical studies as well as literature and application surveys, are confirmed by the conclusions coming from analyzing a case study of electrification of the actuation system of a fullscale pipe handling machine.

Electric powertrains offer higher efficiencies, lower emissions, improved maneuverability and positioning accuracy, reduced environmental impact, smaller footprint, as well as lighter and more compact drivetrain designs, just to name a few of their advantages. Although hydraulic actuation systems are still prevalent in some specific applications (e.g. well-established hydraulic linear drives, energy accumulators, or higher power density in general), it is expected that electric drivetrains will become increasingly popular. This is dictated by the progressive move of production into more hostile and remote environments, where the benefits of the latter solution are dominant. Likewise, the developing need for robotic drilling systems, or automated drilling in general, as well as an increasing attention that the subsea systems attract, all call for efficient, easy to maintain, and reliable powertrain designs.

\section{Acknowledgments}

Trond Ove Nygård from MHWirth AS is acknowledged for providing useful information and documents regarding the Gantry Crane machine.

The research presented in this paper has received funding from the Norwegian Research Council within the Industrial $\mathrm{PhD}$ scheme, project number 231963.

The company MHWirth AS is an industrial partner in the SFI Offshore Mechatronics project co-funded by the Norwegian Research Council: https://sfi.mechatronics.no/.

\section{References}

Aadland, A.-K. and Petersen, K. Subsea all electric. In Offshore Technology Conference. pages 1-8, 2010. doi:10.4043/20927-MS.

Abicht, D. DC electric standalone choke. In SPE Production and Operations Conference and Exhibition. pages 1-7, 2010. doi:10.2118/133441-MS.

ABS. ABS guidance notes on control of harmonics in electrical power systems. American Bureau of Shipping, 2006.

Ådnanes, A. K. Maritime Electrical Installations and Diesel Electric Propulsion. ABB, 2003.

Albert, A., Aamo, O. M., Godhavn, J. M., and Pavlov, A. Suppressing pressure oscillations in offshore drilling: Control design and experimental results. IEEE Transactions on Control Systems Technology, 2015. 23(2):813-819. doi:10.1109/TCST.2014.2332541.

Allaverdi, D., Herberg, A., and Lindemann, U. Lifecycle perspective on uncertainty and value robustness in the offshore drilling industry. In Systems Conference (SysCon), 2013 IEEE International. pages 886-893, 2013. doi:10.1109/SysCon.2013.6549989.

Allen, H. G. and Scott, P. Semi-automatic drilling rig. In SPE Automation Symposium. pages 65-70, 1966. doi:10.2118/1378-MS.

Andrus, J. L., Lewis, R. L., and Anderson, H. B. A new concept in offshore drilling rig power distribution. In Symposium on Offshore Technology and Operations. pages 1-15, 1966. doi:10.2118/1405-MS.

Austigard, A. Robotic Drilling Systems. http://rds . no, 2016. Accessed: 2016-03-14.

Bak, M. K. Model Based Design of Electro-Hydraulic Motion Control Systems for Offshore Pipe Handling Equipment. Ph.D. thesis, Univeristy of Agder, 2014. 
Bak, M. K. and Hansen, M. R. Analysis of offshore knuckle boom crane - part one: Modeling and parameter identification. Modeling, Identification and Control, 2013a. 34(4):157-174. doi:10.4173/mic.2013.4.1.

Bak, M. K. and Hansen, M. R. Analysis of offshore knuckle boom crane - part two: Motion control. Modeling, Identification and Control, 2013b. 34(4):175-181. doi:10.4173/mic.2013.4.2.

Bak, M. K. and Hansen, M. R. Model based design optimization of operational reliability in offshore boom cranes. International Journal of Fluid Power, 2013c. 14(3):53-65. doi:10.1080/14399776.2013.10801413.

Bender, F. A., Kaszynski, M., and Sawodny, O. Drive cycle prediction and energy management optimization for hybrid hydraulic vehicles. IEEE Transactions on Vehicular Technology, 2013. 62(8):35813592. doi:10.1109/TVT.2013.2259645.

Blaschke, F. The principle of field orientation applied to the new transvector closed loop control system for rotating field machines. Siemens Rev, 1972. 34:217220.

Boglietti, A., Cavagnino, A., Tenconi, A., Vaschetto, S., and di Torino, P. The safety critical electric machines and drives in the more electric aircraft: A survey. In Industrial Electronics Society, IECON 2009 - 35th Annual Conference of the IEEE. pages 25872594, 2009. doi:10.1109/IECON.2009.5415238.

BP. Energy Outlook 2016. 2016.

Breyholtz, Ø. and Nikolaou, M. Drilling automation: presenting a framework for automated operations. SPE Drilling \& Completion, 2012. 27(1):118-126. doi:10.2118/158109-PA.

Brinner, T. R., McCoy, R. H., and Kopecky, T. Induction versus permanent-magnet motors for electric submersible pump field and laboratory comparisons. IEEE Transactions on Industry Applications, 2014. 50(1):174-181. doi:10.1109/TIA.2013.2288203.

Christensen, M. L. and Zimmerman, D. L. Optimization of offshore electrical power systems. IEEE Transactions on Industry Applications, 1986. IA22(1):148-160. doi:10.1109/TIA.1986.4504696.

Christopoulos, G. A., Safacas, A. N., and Zafiris, A. Energy savings and operation improvement of rotating cement kiln by the implementation of a unique new drive system. IET Electric Power Applications, 2016. 10(2):101-109. doi:10.1049/iet-epa.2015.0063.
Ciechanowska, M. Hydrocarbonic potential of the Arctic. Nafta $i$ Gaz, 2011. 68(12):1176-1182.

Couper, J. R., Penney, W. R., Fair, J. R., and Walas, S. M. Chemical Process Equipment - Selection and Design. Elsevier, 3rd edition edition, 2012.

Craig, C. and Islam, M. Integrated power system design for offshore energy vessels and deepwater drilling rigs. IEEE Transactions on Industry Applications, 2012. 48(4):1251-1257. doi:10.1109/TIA.2012.2200091.

Depenbrock, M. Direkte Selbstregelung (DSR) für hochdynamische Drehfeldantriebe mit Stromrichterspeisung. ETZ Archive, 1985. 7:211-218.

DNV. Electrical Installations. Offshore Standards DNV-OS-D201, 2005.

Downton, G. Systems modeling and design of automated-directional-drilling systems. SPE Drilling \& Completion, 2015. 27(1):212-232. doi:10.2118/170644-PA.

Gallant, T. A. and Andrews, K. M. Large cage induction motors for offshore machinery drive applications. In Petroleum and Chemical Industry Conference. pages 1155-1159, 2006.

Geyer, T., Papafotiou, G., and Morari, M. Model predictive Direct Torque Control - part I: Concept, algorithm, and analysis. Industrial Electronics, IEEE Transactions on, 2009. 56(6):1894-1905. doi:10.1109/TIE.2008.2007030.

Han, D. K. and Chang, J. H. Design of electromagnetic linear actuator using the equivalent magnetic circuit method. IEEE Transactions on Magnetics, 2016. 52(3):1-4. doi:10.1109/TMAG.2015.2498198.

Hansen, J. F. and Wendt, F. History and state of the art in commercial electric ship propulsion, integrated power systems, and future trends. Proceedings of the IEEE, 2015. 103(12):2229-2242. doi:10.1109/JPROC.2015.2458990.

Harsem, O., Eide, A., and Heen, K. Factors influencing future oil and gas prospects in the Arctic. Energy Policy, 2011. 39(12):8037-8045. doi:10.1016/j.enpol.2011.09.058.

Hazel, T., Baerd, H. H., Legeay, J. J., and Bremnes, J. J. Taking power distribution under the sea: design, manufacture, and assembly of a subsea electrical distribution system. IEEE Industry Applications Magazine, 2013. 19(5):58-67. doi:10.1109/MIAS.2012.2215648. 
Hoevenaars, A. H., Evans, I. C., and Desai, B. Preventing AC drive failures due to commutation notches on a drilling rig. IEEE Transactions on Industry Applications, 2013. 49(3):1215-1220. doi:10.1109/TIA.2013.2253078.

Hoevenaars, A. H., McGraw, M., and Rittammer, K. Preventing centrifuge failures due to voltage distortion on a drilling rig. IEEE Transactions on Industry Applications, 2016. 52(1):633-640. doi:10.1109/TIA.2015.2461620.

Hoevenaars, T., Evans, I. C., and Lawson, A. New marine harmonic standards. IEEE Industry Applications Magazine, 2010. 16(1):16-25. doi:10.1109/MIAS.2009.934965.

IEC. Rotating electrical machines - part 12: Starting performance of single-speed three-phase cage induction motors. IEC 60034-12, 2002.

IEC. Rotating electrical machines - part 1: Rating and performance. IEC 60034-1, 2010.

IEC. Explosive atmospheres - part 1: Equipment protection by flameproof enclosures "d". IEC 60079-1, 2014.

IEC. Explosive atmospheres - part 7: Equipment protection by increased safety "e". IEC 60079-7, 2015.

Isermann, R., Schwarz, R., and Stolzl, S. Fault-tolerant drive-by-wire systems. IEEE Control Systems, 2002. 22(5):64-81. doi:10.1109/MCS.2002.1035218.

Jahmeerbacus, M. I. Flow rate regulation of a variable speed driven pumping system using fuzzy logic. In Electric Power and Energy Conversion Systems (EPECS), 2015 4th International Conference on. pages 1-6, 2015. doi:10.1109/EPECS.2015.7368520.

Janocha, H. Actuators: Basics and Applications. Springer, 2004.

Jernstrøm, T., Sangesland, S., and Hägglin, A. An all-electric system for subsea well control. In Offshore Technology Conference. pages 705-711, 1993. doi:10.4043/7335-MS.

Josifovic, A., Corney, J., and Davies, B. Modeling a variable speed drive for positive displacement pump. In Advanced Intelligent Mechatronics (AIM), 2014 IEEE/ASME International Conference on. pages 1218-1223, 2014. doi:10.1109/AIM.2014.6878248.

Kandukuri, S. T., Klausen, A., Karimi, H. R., and Robbersmyr, K. G. A review of diagnostics and prognostics of low-speed machinery towards wind turbine farm-level health management. Renewable and Sustainable Energy Reviews, 2016. 53:697 - 708. doi:10.1016/j.rser.2015.08.061.

Kaufman, G. A. and Kocher, M. J. Fail-safe dynamic brake for three-phase induction machines. IEEE Transactions on Industry Applications, 1984. IA20(5):1229-1237. doi:10.1109/TIA.1984.4504588.

Kim, J.-H. and Chang, J.-H. A new electromagnetic linear actuator for quick latching. IEEE Transactions on Magnetics, 2007. 43(4):1849-1852. doi:10.1109/TMAG.2006.892289.

Kim, J.-H., Chang, J.-H., Park, S.-M., Hwang, K.I., and Lee, J.-Y. A novel electromagnetic latching device for variable valve timing in automotive engine. In Electromagnetic Field Computation (CEFC), 2010 14th Biennial IEEE Conference on. pages 1-1, 2010. doi:10.1109/CEFC.2010.5481044.

Ko, J., Ko, S., Son, H., Yoo, B., Cheon, J., and Kim, H. Development of brake system and regenerative braking cooperative control algorithm for automatic-transmission-based hybrid electric vehicles. IEEE Transactions on Vehicular Technology, 2015. 64(2):431-440. doi:10.1109/TVT.2014.2325056.

Kozlowski, M. Wound rotor to induction motor and VFD conversion case study. IEEE Transactions on Industry Applications, 2013. 49(3):1221-1227. doi:10.1109/TIA.2013.2251594.

Kremers, N. A. H., Detournay, E., and van de Wouw, N. Model-based robust control of directional drilling systems. IEEE Transactions on Control Systems Technology, 2016. 24(1):226-239. doi:10.1109/TCST.2015.2427255.

Leira, B. J., Chen, Q., Sø rensen, A. J., and Larsen, C. M. Modeling of riser response for DP control. ASME Journal of Offshore Mechanics and Arctic Engineering, 2002. 124(4):219-225. doi:10.1115/1.1491274.

Lujun, Z. Study on an electric drilling rig with hydraulic energy storage. In Computing, Control and Industrial Engineering (CCIE), 2010 International Conference on, volume 2. pages 315-318, 2010. doi:10.1109/CCIE.2010.196.

Marvik, J. I., Øyslebø, E. V., and Korpås, M. Electrification of offshore petroleum installations with offshore wind integration. Renewable Energy, 2013. 50:558-564. doi:10.1016/j.renene.2012.07.010.

Mendel, E., Rauber, T. W., Varejao, F. M., and Batista, R. J. Rolling element bearing fault diagnosis in rotating machines of oil extraction rigs. In 
Signal Processing Conference, 2009 17th European. pages 1602-1606, 2009.

Meritt, H. E. Hydraulic Control Systems. John Wiley \& Sons, 1967.

Mindykowski, J., Tarasiuk, T., Szweda, M., and Evans, I. C. Electric power quality measurements on an all electric ship with active front end propulsion drives. Polish Register of Shipping, Gdynia Maritime University, 2007.

Neufeld, M., Ramirez, O., and Ustinovich, A. A comparative study of fixed speed vs. variable speed control of a series configured pipeline pumping application. In Petroleum and Chemical Industry Technical Conference (PCIC), 2014 IEEE. pages 491-500, 2014. doi:10.1109/PCICon.2014.6961916.

Nordhammer, P. A., Bak, M. K., and Hansen, M. R. Controlling the slewing motion of hydraulically actuated cranes using sequential activation of counterbalance valves. In Control, Automation and Systems (ICCAS), 2012 12th International Conference on. pages 773-778, 2012.

Ottestad, M., Nilsen, N., and Hansen, M. R. Reducing the static friction in hydraulic cylinders by maintaining relative velocity between piston and cylinder. In Control, Automation and Systems (ICCAS), 2012 12th International Conference on. pages 764769, 2012.

Papafotiou, G., Kley, J., Papadopoulos, K., Bohren, P., and Morari, M. Model predictive Direct Torque Control - part II: Implementation and experimental evaluation. Industrial Electronics, IEEE Transactions on, 2009. 56(6):1906-1915. doi:10.1109/TIE.2008.2007032.

Pawlus, W., Choux, M., Hansen, M., and Hovland, G. Load torque estimation method to design electric drivetrains for offshore pipe handling equipment. ASME Journal of Offshore Mechanics and Arctic Engineering, 2016. 138(4):041301:1-9. doi:10.1115/1.4032897.

Pawlus, W., Choux, M., Hovland, G., and Huynh, V. K. Parameters identification of induction motor dynamic model for offshore applications. In Mechatronic and Embedded Systems and Applications (MESA), 2014 IEEE/ASME 10th International Conference on. pages 1-6, 2014a. doi:10.1109/MESA.2014.6935555.

Pawlus, W., Choux, M., Hovland, G., Øydna, S., and Hansen, M. R. Modeling and simulation of an offshore pipe handling machine. In Simulation and
Modeling, 2014 SIMS 55th Conference on. pages 277-284, 2014b.

Pawlus, W., Frick, D., Morari, M., Hovland, G., and Choux, M. Drivetrain design optimization for electrically actuated systems via Mixed Integer Programing. In Industrial Electronics Society, IECON 2015 - 41st Annual Conference of the IEEE. pages 14651470, 2015. doi:10.1109/IECON.2015.7392307.

Pawlus, W., Liland, F., Nilsen, N., Øydna, S., Hovland, G., and Wroldsen, T. K. Optimization of a high fidelity virtual model of a hydraulic hoisting system for real-time simulations. In 8th International Petroleum Technology Conference. pages 1-11, 2014c. doi:10.2523/IPTC-17780-MS.

Pedersen, H. C., Johansen, P., Yigen, C., Andersen, T. O., and Rømer, D. B. Analysis of temperature's influence on a digital displacement pump's volumetric efficiency. $A p$ plied Mechanics and Materials, 2012. 233:24-27. doi:10.4028/www.scientific.net/AMM.233.24.

Petersen, S., Doyle, P., Carlsen, S., van der Linden, J. H., Myhre, B., Sansom, M., Skavhaug, A., Mikkelsen, E., and Sjong, D. A survey of wireless technology for the oil and gas industry. In Intelligent Energy Conference and Exhibition. pages 1-10, 2008. doi:10.2118/112207-MS.

Pettersen, T. Second well in production at Prirazlomnoye. http://bit.1y/22R4BYn, 2015. Accessed: 2016-03-31.

Phillips, R. D. and Laberge, R. N. A smart relief valve. IEEE Transactions on Industry Applications, 1984. IA-20(2):413-417. doi:10.1109/TIA.1984.4504427.

Pipe, T. Subsea hydraulic power generation and distribution for subsea control systems. In European Petroleum Conference. pages 829-835, 1982. doi:10.2118/13399-MS.

Potiani, M. and Motta, E. A review of IC installations: Lessons learned from electric-hydraulic, hydraulic and all-electric systems. In Offshore Technology Conference. pages 1-6, 2014. doi:10.4043/25391MS.

Rahimi, M., Rausand, M., and Wu, S. Reliability prediction of offshore oil and gas equipment for use in an Arctic environment. In International Conference on Quality, Reliability, Risk, Maintenance, and Safety Engineering. pages 81-86, 2011.

Rahman, A. M. and Abdullah, R. Noise survey in offshore operations. In SPE Health, Safety 
and Environment in Oil and Gas Exploration and Production Conference. pages 131-144, 1991. doi:10.2118/23201-MS.

Rassenfoss, S. Drilling automation: A catalyst for change. In Journal of Petroleum Technology. pages 28-34, 2011. doi:10.2118/0911-0028-JPT.

Rhea, T. R. Modern diesel-electric drilling rig equipment. Transactions of the American Institute of Electrical Engineers, 1946. 65(7):447-453. doi:10.1109/T-AIEE.1946.5059368.

Rivenbark, M., Khater, S., Dietz, W., and Barnes, S. An innovative all electric well production system. In SPE Production and Operations Symposium. pages 1-9, 2007. doi:10.2118/67244-MS.

Rizzone, M. L. Electric drilling rig developments. IEEE Transactions on Industry and General Applications, 1967. IGA-3(2):194-197. doi:10.1109/TIGA.1967.4180759.

Rodriguez, J. A., Nasr, H., Scott, M., Al-Jasmi, A. K., Velasquez, G., Goel, H. K., Carvajal, G. A., Cullick, A. S., Bravo, C. E., and Al-Abbasi, A. New generation of petroleum workflow automation: Philosophy and practice. In SPE/IADC Drilling Conference and Exhibition. pages 1-13, 2013. doi:10.2118/163812MS.

Roemer, D. B., Bech, M. M., Johansen, P., and Pedersen, H. C. Optimum design of a moving coil actuator for fast-switching valves in digital hydraulic pumps and motors. IEEE/ASME Transactions on Mechatronics, 2015. 20(6):2761-2770. doi:10.1109/TMECH.2015.2410994.

Rye, J. G. Offshore drilling trends. In SPE California Regional Meeting. pages 1-5, 1972. doi:10.2118/4188-MS.

Sadlier, A. G. and Laing, M. L. Interoperability: An enabler for drilling automation and a driver for innovation. In SPE/IADC Drilling Conference and Exhibition. pages 1-12, 2011. doi:10.2118/140114-MS.

Sakuraba, J., Hata, F., Kung, C. C., Sotooka, K., Mori, H., and Takarada, N. Development of superconducting electric ship propulsion system. In The Second International Offshore and Polar Engineering Conference. pages 1-7, 1992.

Schmidt, L. Robust Control of Industrial Hydraulic Cylinder Drives - with Special Reference to Sliding Mode- 85 Finite-Time Control. Ph.D. thesis, Aalborg University, 2015.
Seggewiss, G., Dai, J., and Fanslow, M. Synchronous motors on grinding mills: the different excitation types and resulting performance characteristics with VFD control for new or retrofit installations. IEEE Industry Applications Magazine, 2015. 21(6):60-67. doi:10.1109/MIAS.2014.2345821.

Shatto, H. L. Diesel electric drilling. In 3rd World Petroleum Congress. pages 127-143, 1951.

Shuguang, L., Yunheng, C., Chenhui, J., and Yamin, T. Design of electric and control system of offshore drilling rig and its key technologies. In Control and Decision Conference (CCDC), 2015 27th Chinese. pages 4288-4293, 2015. doi:10.1109/CCDC.2015.7162684.

Springett, F. B., Shelton, A. D., Swain, J. A., Valdez, H. F., Goetz, C. A., Wong, N., Womer, K. A., and Killalea, M. Advanced rig technology - future technology subcommittee report of activities and industry survey results. In IADC/SPE Drilling Conference and Exhibition. pages 1-10, 2010. doi:10.2118/128953-MS.

Stone, F. M., Bishop, D. N., Cospolich, J. D., Mahl, G. J., Stewart, D. R., and Stewart, H. R. Update: offshore electrical installation practices. IEEE Industry Applications Magazine, 2001. 7(1):56-63. doi:10.1109/2943.893365.

Strickler, J. D. Electrified offshore drilling and production facilities on island esther. IEEE Transactions on Industry and General Applications, 1967. IGA3(1):43-51. doi:10.1109/TIGA.1967.4180738.

Sun, Z. and Kuo, T. W. Transient control of electro-hydraulic fully flexible engine valve actuation system. IEEE Transactions on Control Systems Technology, 2010. 18(3):613-621. doi:10.1109/TCST.2009.2025188.

Swamy, M. M., Kang, J.-K., and Shirabe, K. Power loss, system efficiency, and leakage current comparison between $\mathrm{Si}$ IGBT VFD and SiC FET VFD with various filtering options. IEEE Transactions on Industry Applications, 2015. 51(5):3858-3866. doi:10.1109/TIA.2015.2420616.

Thorsen, O. and Dalva, M. A survey of faults on induction motors in offshore oil industry, petrochemical industry, gas terminals, and oil refineries. Industry Applications, IEEE Transactions on, 1995. 31(5):1186-1196. doi:10.1109/28.464536.

Tiitinen, P. and Surandra, M. The next generation motor control method, DTC direct torque control. In Power Electronics, Drives and Energy Systems 
for Industrial Growth, 1996., Proceedings of the 1996 International Conference on, volume 1. pages 37-43, 1996. doi:10.1109/PEDES.1996.537279.

Ummaneni, R. B., Nilssen, R., and Brennvall, J. E. Force analysis in design of high power linear permanent magnet actuator with gas springs in drilling applications. In Electric Machines Drives Conference, 200\%. IEMDC '0\%. IEEE International. pages 285-288, 2007. doi:10.1109/IEMDC.2007.382680.

Voltz, D. A., Beaver, S. C., and McDonald, C. L. The right mix of drivers and power generation. IEEE Industry Applications Magazine, 2004. 10(6):43-52. doi:10.1109/MIA.2004.1353046.

Wang, F. and Stelson, K. A. An efficient fan drive system based on a novel hydraulic transmission. IEEE/ASME Transactions on Mechatronics, $2015 . \quad 20(5): 2234-2241$. doi:10.1109/TMECH.2014.2370893.

de Wardt, J. P., Behounek, M., Chapman, C., and Putra, D. Drilling systems automation - preparing for the big jump forward. In SPE/IADC Drilling Conference and Exhibition. pages 1-16, 2013. doi:10.2118/163422-MS.

Williams, M. Top-drive drilling systems: electric vs. hydraulic - a technical overview and comparison. In SPE/IADC Drilling Conference. pages 539-548, 1991. doi:10.2118/21958-MS.

Woodacre, J., Bauer, R., and Irani, R. A review of vertical motion heave compensation systems. Ocean Engineering, 2015. 104:140 - 154. doi:http://dx.doi.org/10.1016/j.oceaneng.2015.05.004.

Yadav, P., Kumar, R., Panda, S. K., and Chang, C. S. Optimal thrust allocation for semisubmersible oil rig platforms using improved harmony search algorithm. IEEE Journal of Oceanic Engineering, 2014. 39(3):526-539. doi:10.1109/JOE.2013.2270017.

Yoon, J. I., Kwan, A. K., and Truong, D. Q. A study on an energy saving electro-hydraulic excavator. In ICCAS-SICE, 2009. pages 3825-3830, 2009.

Zacks Equity Research. Eni Announces First Oil Yield from Goliat Field Off Norway. http://bit.ly/ 1ZMFZug, 2016. Accessed: 2016-03-31.

Zhang, S., Norum, L., Nilssen, R., and Lorenz, R. D. Down-The-Hole hammer drilling system driven by a tubular reciprocating translational motion permanent magnet synchronous motor. In Industrial Electronics (ISIE), 2012 IEEE International Symposium on. pages 647-651, 2012. doi:10.1109/ISIE.2012.6237165.
Zolotukhin, A. and Gawrilov, V. Russian Arctic petroleum resources. Oil and Gas Science and Technology, 2011. 66(6):899-910. doi:10.2516/ogst/2011141. 